\title{
Thyroid Metastasis of Renal Cell Carcinoma
}

\author{
${ }^{1}$ Bulent Citgez, ${ }^{1}$ Mehmet Uludag, ${ }^{1}$ Gurkan Yetkin, ${ }^{1}$ Esin Kabul Gurbulak \\ ${ }^{2}$ Banu Yilmaz Ozguven, ${ }^{3}$ Sinharib Citgez, ${ }^{3}$ Veli Yalcin \\ ${ }^{1}$ Department of General Surgery, Sisli Etfal Training and Research Hospital, Istanbul, Turkey \\ ${ }^{2}$ Department of Pathology, Sisli Etfal Training and Research Hospital, Istanbul, Turkey \\ ${ }^{3}$ Department of Urology, Cerrahpasa School of Medicine, University of Istanbul, Istanbul, Turkey
}

Correspondence: Bulent Citgez, Department of General Surgery, Yavuklular Sokak Gul, Apartment No. 1, D-3 Bakirkoy, Istanbul Turkey, Phone: +90-505-2376847, Fax: +90-212-5713570, e-mail: bcitgez@yahoo.com

\section{ABSTRACT}

Metastases to the thyroid gland are rare. We report the case of a 50-year-old man with an isolated thyroid metastasis from renal cell carcinoma (RCC), 3 years after radical nephrectomy for the primary disease. Although uncommon, if a patient with a previous history of malignancy has a new thyroid mass, it should be considered metastatic tumor of recurrent malignancy until proved otherwise.

Keywords: Thyroid, Metastasis, Renal cell carcinoma.

\section{INTRODUCTION}

Metastasis of carcinomas to the thyroid gland is rare. The most common metastatic tumor to the thyroid is renal cell carcinomas (RCC). ${ }^{1}$ Other reported tumors metastasing to the thyroid include lung cancer, breast carcinoma, nasopharyngeal carcinoma, malignant melanoma and leiomyosarcoma. ${ }^{2,3}$

The incidence of metastatic thyroid tumors among all thyroid malignancies is $1.2 \% .^{3}$ Reports emphasize poor prognosis of patients with thyroid metastasis. ${ }^{2,4} \mathrm{~A}$ case of thyroid metastasis of the kidney, who had undergone a radical nephrectomy for renal cell carcinoma, 3 years earlier, is described with clinicopathological features and literature review.

\section{CASE REPORT}

A 50-year-old man underwent a right nephrectomy for RCC on October 2007. The tumor of the kidney had been incidentally detected on ultrasonography. During nephrectomy, the tumor had been determined to be $4 \times 2.5 \times 1 \mathrm{~cm}$ in size, encapsulated and showed no invasion into surrounding tissues in the lower pole of the right kidney. The histological examination showed the tumor to be renal cell carcinoma (RCC). The patient had been discharged uneventfully. On May 2010, he was referred to our department with enlargement of his neck. The patient had goiter on physical examination. Ultrasound revealed a hypoechoic, heterogenous, solid nodule which measured $34 \times 37 \mathrm{~mm}$ in size, occupied the left lobe and isthmus of the thyroid gland and other multiple nodules in both thyroid lobes. Fine needle aspiration biopsy indicated a cellular adenomatoid nodule containing rich microfollicles. However, due to growth of the thyroid nodule within such a short time and considering the possibility of a thyroid malignancy, a thyroidectomy was planned. He underwent a bilateral total thyroidectomy. The tumor was identical to RCC on histological examination. Immunohistochemical staining determined positive stains for CD10 (Fig. 1) and epithelial membrane antigen (EMA) but negative stains for thyroid transcription factor-1 (TTF-1), calcitonin, synaptophysin, chromogranin. The diagnosis was established as a metastatic thyroid tumor of RCC (Fig. 2). Postoperative bone scintigraphy and computed tomography (CT) studies detected neither metastatic focus nor abnormality. The patient is being followed up and no evidence of recurrence has been obtained.

\section{DISCUSSION}

From autopsy studies, the incidence of metastatic tumors to the thyroid ranges from 1.9 to $25 \%{ }^{5}$ The most common primary site was breast, lung and kidney. ${ }^{5}$ Chen et al reported 10 patients with thyroid metastases and $50 \%$ of these patients had metastases from renal cell carcinoma. In fact, RCC is clinically the most common metastatic tumor to the thyroid. RCC accounts for 80 to $85 \%$ of the malignant renal tumors. The disease has a wide range of heterogeneity of clinical presentation. The diagnosis of RCC can be established either incidentally or during the late stage of the disease when the tumor grows to a big size. $^{6}$ In one-third of cases, RCC is localized concurrently in both kidneys. Tumor metastases to the lung, bone, liver and brain occur frequently. Moreover, metastases to the thyroid, soft tissue, colon, muscle and any other organ can be found. ${ }^{6,7}$ In our present case, renal tumor had been detected incidentally. After right radical nephrectomy, RCC had been showed on histological examination.

Although some patients with metastatic disease to the thyroid present with symptoms, such as dysphagia, stridor, hoarseness or a palpable neck mass, most of the patients are 


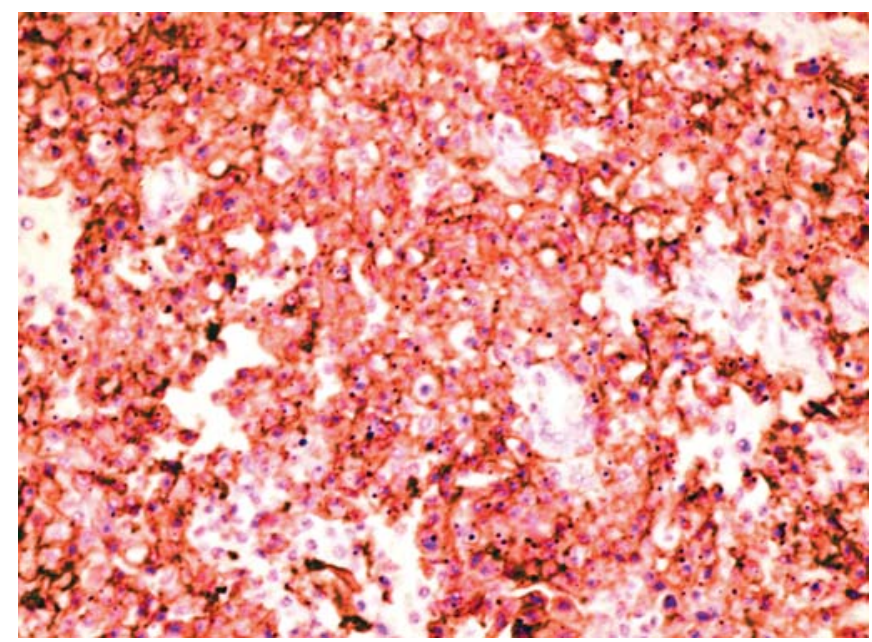

Fig. 1: Immunohistochemical staining determined positive stains for CD10 and EMA but negative stains for TTF-1, calcitonin, synaptophysin, chromogranin

asymptomatic at presentation. ${ }^{5}$ Therefore, most of these patients have their metastases discovered by routine follow-up physical examinations or imaging studies after resection of the primary tumor and are asymptomatic for years similiar to our case. ${ }^{8}$ Chen et al showed that the median interval from the initial treatment of the primary tumor to resection of the thyroid metastases was 2 years, also some cases without metastases have been reported. ${ }^{9}$ In our case, the patient had a rapid-growing nodule in his neck which was initially diagnosed as multinoduler goiter 3 years after resection of primary tumor and a correct diagnosis of metastatic thyroid tumor was established after thyroidectomy and histological examinations.

Fine needle aspiration biopsy has been suggested as a diagnostic study for metastatic thyroid tumors. ${ }^{5,10}$ In any patient with a previous history of malignancy, no matter how remote that history is, a new thyroid mass should be considered recurrent malignant until proved otherwise. ${ }^{11}$ It is reported that making diagnosis of metastatic thyroid tumors is difficult and challenging due to the long time period between diagnosis of the primary tumor and detecting metastasis, the presence of small solitary lesions in the thyroid gland and that most cases are asymptomatic. ${ }^{12}$ In our present case, the result of fine needle aspiration cytology was unremarkable.

Another diagnostic problem is distinguishing metastatic thyroid clear cell carcinoma from clear cell changes in primary thyroid tumors. ${ }^{10,13}$ In these cases, immunohistochemical staining could provide much more information for differential diagnosis. Metastatic thyroid tumors should have negative stains for calcitonin and thyroglobulin. ${ }^{14}$ In the present case, immunochemical staining determined negative stains for thyroglobulin and calcitonin.

There is no clear consensus regarding the treatment of metastatic disease to the thyroid. ${ }^{5,15}$ Most authors recommend a thyroid lobectomy and isthmusectomy in the absence of other metastatic disease or for palliation of airway obstruction. ${ }^{1,5,15}$ Machens et al recommended total thyroidectomy because metastatic disease can be detected after years of the treatment of primary tumor in the other lobe after initial lobectomy. ${ }^{16}$

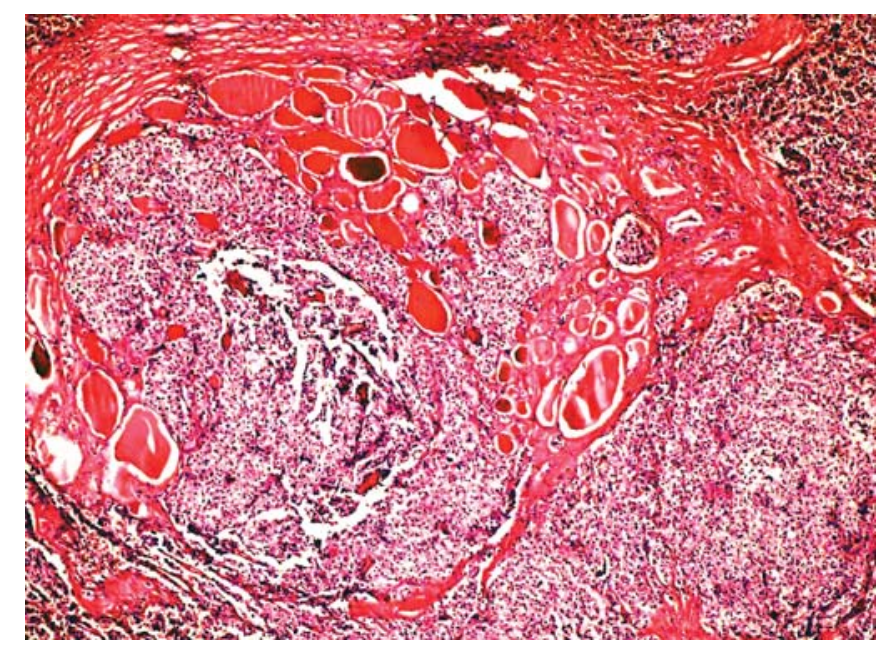

Fig. 2: Neoplastic infiltration surrounding the thyroid follicles

Chen et al reported that $60 \%$ of the patients with isolated thyroid metastases were still alive after a thyroidectomy during a median follow-up period of 5.2 years. ${ }^{5}$ In this context, he recommended total thyroidectomy in the absence of locally recurrent disease and an extrathyroidal metastasis. ${ }^{5}$

Although the patient with thyroid nodule is regarded primarily as tumors of the thyroid, thyroid metastases should be kept in mind in patients previously operated for malignancy, as seen in our case.

\section{REFERENCES}

1. Wood K, Vini L, Harmer C. Metastases to the thyroid gland: The royal marsden experience. Eur J Surg Oncol 2004;30: 583-88.

2. Menegaux F, Chigot JP. Thyroid metastases. Ann Chir 2001;126:981-84.

3. Lam KY, Lo CY. Metastatic tumors to the thyroid gland: A study of 79 cases in chinese patients. Arch Pathol Lab Med 1998;122:37-41.

4. Dequanter D, Lothaire P, Larsimont D de Saint-Aubain de Somerhausen N, Andry G. Intrathyroid metastasis: 11 cases. Ann Endocrinol 2004;65(3):205-08.

5. Chen H, Nicol TL, Udelsman R. Clinically significant, isolated metastatic disease to thyroid gland. World J Surg 1999;23: 177-81.

6. Ritchie AW, Chisholm GD. The natural history of renal carcinoma. Semin Oncol 1983;10:390-400.

7. Yetkin G, Uludag M, Ozagari A. Solitary colonic metastasis of renal cell carcinoma. Acta Chir Belg Mar-Apr 2008;108(2): 264-65.

8. Ericsson $\mathrm{M}$, Biorklund $\mathrm{A}$, Cederquist $\mathrm{E}$, Ingemansson $\mathrm{S}$, Akerman M. Surgical treatment of metastatic disease in the thyroid gland. J Surg Oncol 1981;17(1):15-23.

9. Shima H, Mori H, Takahashi M, Nakamura S, Miura K, Tarao M. A case of renal cell carcinoma solitarily metastasized to thyroid 20 years after the resection of primary tumor. Pathol Res Pract May 1985;179(6):666-72.

10. Seki H, Ueda T, Shibata Y, Sato Y, Yagihashi N. Solitary thyroid metastasis of renal clear cell carcinoma: Report of a case. Surg Today 2001;31(3):225-29.

11. Nakhjavani MK, Gharib H, Goellner JR, van Heerden JA. Metastases to the thyroid gland: A report of 43 cases. Cancer 1 Feb 1997;79(3):574-78. 
12. Lam KY, Lo CY. Metastatic tumors to the thyroid gland: A study of 79 cases in Chinese patients. Arch Pathol Lab Med 1998;122:37-41.

13. Dionigi G, Uccella S, Gandolfo M, Lai A, Bertocchi V, Rovera F, Tanda ML. Solitary intrathyroidal metastasis of renal clear cell carcinoma in a toxic substernal multinodular goiter. Thyroid Res 24 Oct 2008;1(1):6.

14. Shimizu K, Nagahama M, Kitamura Y, Chin K, Kitagawa W, Shibuya T, Mimura T, Ozaki O, Sugino K, Ito K. Clinico- pathological study of clearcell tumors of the thyroid: An evaluation of 22 cases. Surg Today 1995;25:1015-22.

15. McCabe DP, Farrar WB, Petkov TM, Finkelmeier W, O’Dwyer P, James A. Clinical and pathologic correlations in disease metastatic to the thyroid gland. Am J Surg Oct 1985; 150(4):519-23.

16. Machens A, Dralle H. Outcome after thyroid surgery for metastasis from renal cell cancer. Surgery Jan 2010;147(1): 65-71 (Epub 2009 Oct 30). 